\title{
Linezolid Add-On Rescue Therapy Cured MRSA Necrotizing Pneumonia: a case report in a preterm infant
}

\author{
Abbas Moosa Al-Omran a, Sameer Yaseen Al-Abdi ${ }^{\text {b, c, d }}$, Hasan Mohammad Al-Amer ${ }^{\text {e }}$ \\ ${ }^{\text {a }}$ Department of Pediatrics, Almana General Hospital, Al-Ahsa, Saudi Arabia \\ ${ }^{b}$ Department of Pediatrics, King Abdulaziz Hospital, Ministry of the National Guard-Health Affairs, Al-Ahsa, Saudi \\ Arabia; ${ }^{c}$ King Abdullah International Medical Research Center, Al-Ahsa, Saudi Arabia; ${ }^{d}$ King Saud Bin Abdulaziz \\ University for Health Sciences, Al-Ahsa, Saudi Arabia. \\ ${ }^{\text {e }}$ Department of Pediatrics, Maternity and Children Hospital, Al-Ahsa, Saudi Arabia
}

\begin{abstract}
Necrotizing pneumonia due to Methicillin-Resistant Staphylococcus Aureus (MRSA) is devastating and difficult to treat in preterm infants. We report a case of severe MRSA necrotizing pneumonia in a preterm infant. As an add-on rescue therapy to vancomycin, linezolid rapidly cured this case after the failure of vancomycin plus rifampicin. This rapid cure suggests that adjunctive rather than rescue linezolid may be considered in such cases.
\end{abstract}

Keywords: Preterm infant, Necrotizing pneumonia, Methicillin-Resistant Staphylococcus Aureus (MRSA), Pneumatoceles, Linezolid, Vancomycin, Rifampicin.

\section{Introduction}

Methicillin-Resistant Staphylococcus Aureus (MRSA) was the causative organism in $1.4 \%$ of the neonatal late-onset sepsis (LOS) in Arab states in the Gulf region [1]. MRSA colonization is a risk factor for invasive MRSA infections. Preterm infants born at < 32 weeks' gestation or weighing < 1500 grams are at two-fold increased risk of MRSA colonization [2].

MRSA necrotizing pneumonia is associated with high mortality in preterm infants and its treatment is a challenge [3-7]. Vancomycin monotherapy is the standard treatment for MRSA necrotizing pneumonia [6-8]. Sometimes, vancomycin fails to treat MRSA necrotizing pneumonia because of poor lung penetration and the emergence of vancomycin-resistant MRSA strains [7, 9-14]. Linezolid penetrates cells, tissues, and MRSA biofilm better than vancomycin $[14,15]$. Linezolid has been advocated as an alternative, second line, or rescue treatment $[6,11,13-16]$. In December 2000, linezolid was approved for use in preterm infants in the USA [8, 13], but it is still off-label in few European countries $[16,17]$. The available supporting evidence for its use in preterm infants is based on one small open-label randomized clinical trial [18], case series [19-23], and case reports [13, 16].

Moreover, combining linezolid with vancomycin is controversial as in-vitro studies have shown that linezolid decreased vancomycin activity [24-27]. Thus, we aimed to report linezolid as an add-on rescue treatment for severe MRSA necrotizing pneumonia in a preterm infant. Hoping this report will increase awareness of newborn infant caregivers on the appropriate use of linezolid for invasive MRSA infections. 


\section{Case Report}

The patient was a female very preterm newborn infant with a birth weight of 1440 grams. She was born at 30 weeks' gestation by emergency Cesarean section due to maternal pre-eclamptic toxemia. The mother was 26 years old primigravida who received adequate intrapartum antibiotic prophylaxis as she had Group B streptococcus bacteriuria at 22 weeks' gestation. Apgar scores were 5 and 8 at 1 and 5 minutes, respectively. The infant was started on ampicillin and cefotaxime, which were discontinued on the $3^{\text {rd }}$ day of life (DOL) when her blood culture was reported negative. She required two doses of surfactant and invasive conventional mechanical ventilation (ICMV) for 3 days. The cord screening for glucose-6- phosphate dehydrogenase showed that she is deficient. Her metabolic screen was not remarkable.

On the $8^{\text {th }} \mathrm{DOL}$, she developed progressive respiratory distress for which she required ICMV again. LOS was entertained, and she was investigated and treated accordingly. The chest X-ray showed a small pneumatocele in the left middle lung zone. Vancomycin and ceftazidime were started empirically. Analysis of the cerebrospinal fluid was normal and its culture as well as the urine culture were sterile. The blood culture on the $8^{\text {th }}$ DOL grew MRSA sensitive to vancomycin and rifampicin. Vancomycin plus rifampicin combination cleared the bacteremia but failed to treat the progressive necrotizing pneumonia. Repeated trough vancomycin levels were within the therapeutic range. Her respiratory status continued to deteriorate until day 17 post-MRSA necrotizing pneumonia when rifampicin was replaced by intravenous linezolid $(10 \mathrm{mg} / \mathrm{kg}$ every 8 hours). After that, she showed a rapid, significant improvement; CRP dropped to $49 \mathrm{mg} / \mathrm{L}$ and platelets' count normalized three days after adding linezolid. The infant was weaned gradually from the respiratory support and was on room air on day 37 post-MRSA necrotizing pneumonia. Figure 1 summarizes the timeline events and Figure 2 shows serial chest radiological images. Cranial ultrasound scans revealed no evidence of intraventricular hemorrhage. Ophthalmology screening for retinopathy of prematurity was negative. Hearing assessment by otoacoustic emissions was normal bilaterally. The infant had no central line before acquiring MRSA infection.

She was discharged home on $52^{\text {nd }} \mathrm{DOL}\left(37^{3 / 7}\right.$ postmenstrual weeks). On discharge, she was on room air, feeding orally well, and weighing 2185 grams. A repeated chest X-ray at four months of age was completely normal (Figure 2-C). She had normal growth and development when she was discharged from the high-risk newborn clinic at nine months of age.

\section{Discussion}

As an add-on rescue therapy to vancomycin, linezolid rapidly cured severe MRSA necrotizing pneumonia in a preterm infant after the failure of vancomycin plus rifampicin. This rapid cure suggests that adjunctive rather than rescue linezolid needs to be considered in such cases. 
During the last two decays, linezolid was the only approved anti-MRSA on infants among the other new antibiotics that have been approved in adults [8]. Linezolid has several advantages over vancomycin, including oral route, less renal toxicity, less sensitivity reaction, and no need for therapeutic drug monitoring $[12,14,18]$. On the other hand, linezolid is associated with more thrombocytopenia and anemia than vancomycin $[8,18-20,22,28]$. Thus, it is recommended to monitor platelets and hemoglobin levels during linezolid treatment [18, 20]. Pediatric and adult literature have reported the following side effects of linezolid: peripheral and optic neuropathy [11, 29]; cataract [28]; hyperlactatemia [19, 29, 30]; serotonin syndrome [29]; and dental discoloration [31]. It seems that these side effects are transient and cumulative dose-dependent $[22,28,29]$.

Linezolid inhibits bacterial growth by binding to the bacterial 505 ribosomal subunit preventing the formation of the 70 S ribosomal complex $[8,16,19]$. So, linezolid is a bacteriostatic antibiotic, whereas vancomycin and rifampicin are bactericidal antibiotics $[8,9,11]$. The dogma of bacteriostatic antibiotics antagonize bactericidal antibiotics [32] has been demonstrated by in-vitro studies on combining linezolid with vancomycin [24-27]. Despite that rifampicin penetrates cells, tissues, and biofilms better than vancomycin [9], vancomycin plus rifampicin failed to treat MRSA necrotizing pneumonia in our case. We have no plausible explanation of why the combination of two bactericidal antibiotics failed whereas a bactericidal plus a bacteriostatic antibiotics succeeded except that tissue penetration of linezolid is better than rifampicin. An in vitro study has demonstrated that linezolid plus rifampicin is more potent than linezolid plus vancomycin [26]. On the other hand, MRSA resistance to linezolid has been reported in Saudi Arabia [33], thus using linezolid needs to be through a stewardship program or individualized after consulting the infectious diseases team [11].

In conclusion, linezolid, as an add-on rescue therapy to vancomycin, rapidly cured severe MRSA necrotizing pneumonia in a preterm infant after the failure of vancomycin plus rifampicin. Proper hand hygiene is the best way to prevent healthcare-associated MRSA infections and, subsequently, improve preterm infants' outcomes.

Figure 1. Timeline summarized events of MRSA necrotizing pneumonia.

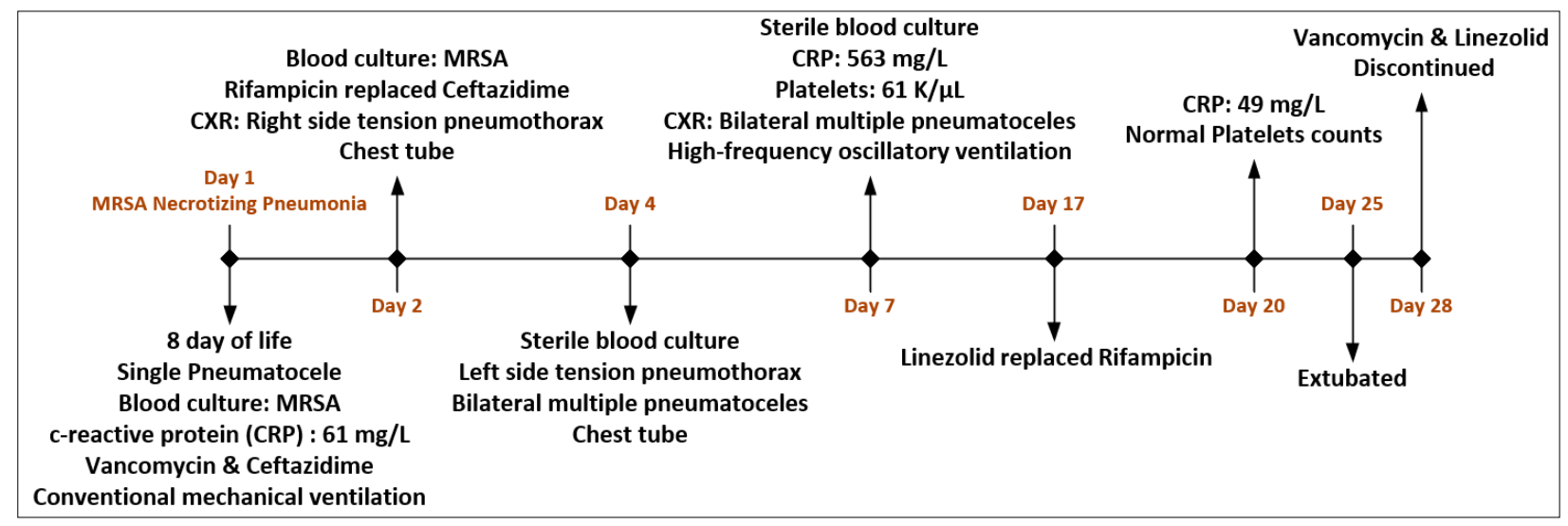


Figure 2. Serial chest X-rays showing the chronological clinical course of necrotizing pneumonia.

White arrows indicate Pneumatocele and Yellow arrows indicate pneumothorax

A. Chest $\mathrm{X}$-rays and $\mathrm{CT}$ scan during vancomycin and rifampicin treatment:
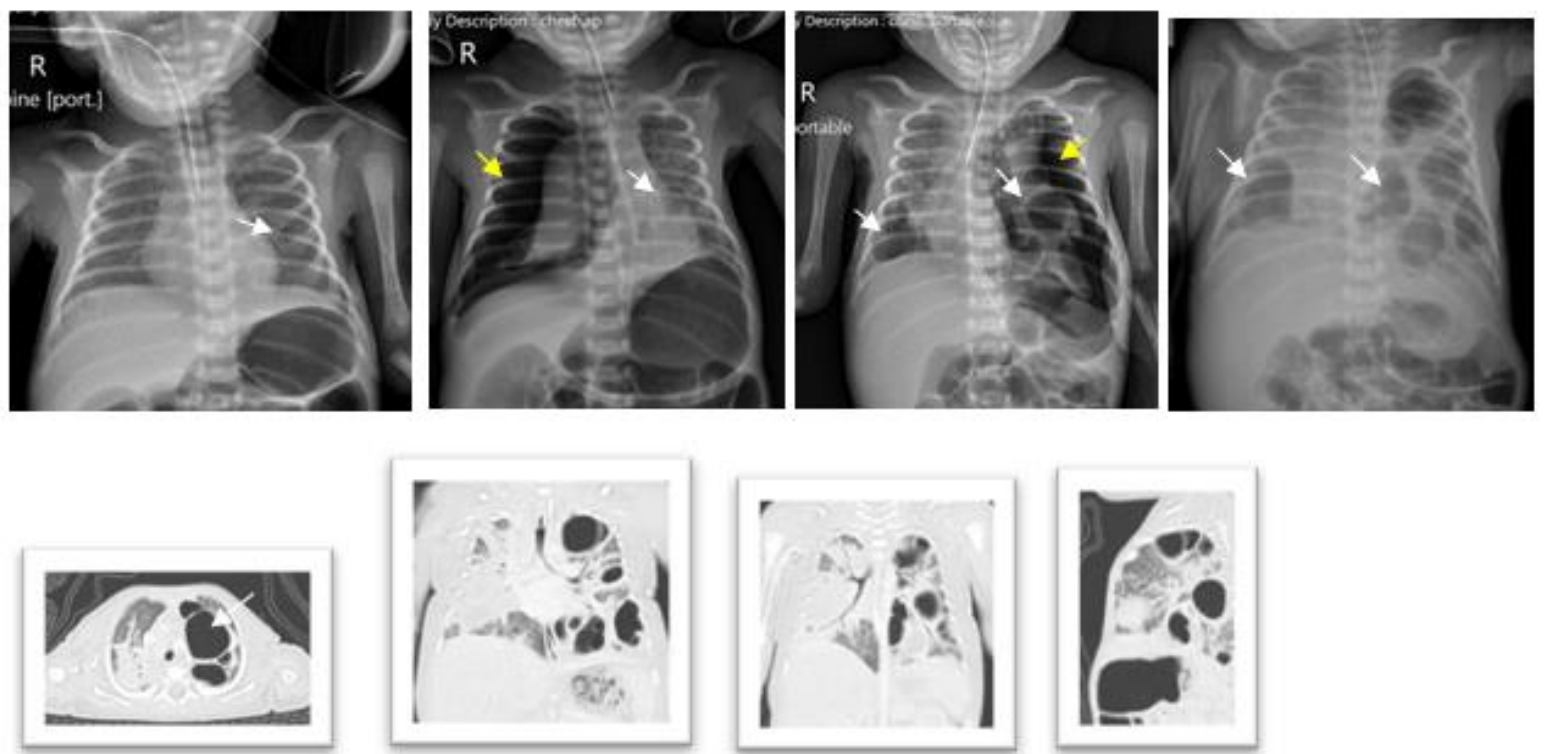

B. Chest $\mathrm{X}$-ray during vancomycin and linezolid treatment:
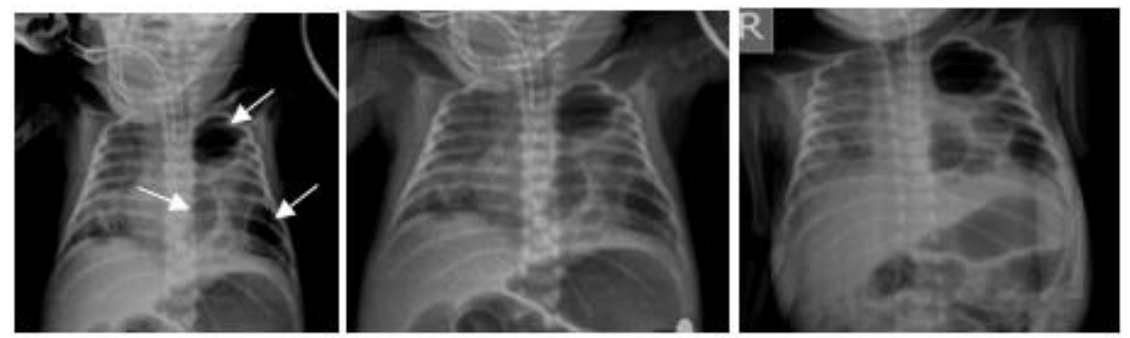

C. Chest X-ray at $\mathbf{4}$ month of age:

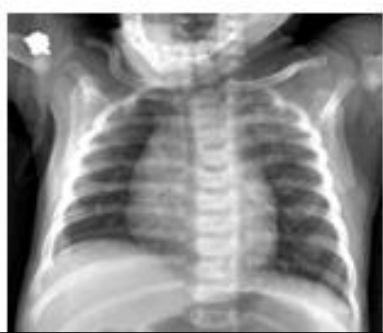

3. Financial support and sponsorship:

Nil.

4. Conflicts of interest:

There are no conflicts of interest. 


\section{Availability of data and materials:}

Data are available from the corresponding author on a reasonable request.

\section{References}

[1] Hammoud MS, Al-Taiar A, Al-Abdi SY, Bozaid H, Khan A, AlMuhairi LM, et al. Late-onset neonatal sepsis in Arab states in the Gulf region: two-year prospective study. International Journal of Infectious Diseases. 2017;55:125-30.

[2] Washam M, Woltmann J, Haberman B, Haslam D, Staat MA. Risk factors for methicillinresistant Staphylococcus aureus colonization in the neonatal intensive care unit: A systematic review and meta-analysis. American journal of infection control. 2017;45:1388-93.

[3] McAdams RM, Mazuchowski E, Ellis MW, Rajnik M. Necrotizing staphylococcal pneumonia in a neonate. J Perinatol. 2005;25:677-9.

[4] Yee-Guardino S, Kumar D, Abughali N, Tuohy M, Hall GS, Kumar ML. Recognition and treatment of neonatal community-associated MRSA pneumonia and bacteremia. Pediatric Pulmonology. 2008;43:203-5.

[5] Kempley S, Kapellou O, McWilliams A, Banerjee J, McCorqodale A, Millar M. Antibiotic treatment duration and prevention of complications in neonatal Staphylococcus aureus bacteraemia. The Journal of hospital infection. 2015;91:129-35.

[6] Hooven TA, Polin RA. Pneumonia. Seminars in fetal \& neonatal medicine. 2017;22:206-13.

[7] Dong Y, Glaser K, Speer CP. New Threats from an Old Foe: Methicillin-Resistant Staphylococcus aureus Infections in Neonates. Neonatology. 2018;114:127-34.

[8] Gostelow M, Gonzalez D, Smith PB, Cohen-Wolkowiez M. Pharmacokinetics and safety of recently approved drugs used to treat methicillin-resistant Staphylococcus aureus infections in infants, children and adults. Expert Review of Clinical Pharmacology. 2014;7:327-40.

[9] Davis JS, van Hal S, Tong SYC. Combination Antibiotic Treatment of Serious MethicillinResistant Staphylococcus aureus Infections. Semin Respir Crit Care Med. 2015;36:003-16. [10] Liu C, Bayer A, Cosgrove SE, Daum RS, Fridkin SK, Gorwitz RJ, et al. Clinical Practice Guidelines by the Infectious Diseases Society of America for the Treatment of MethicillinResistant Staphylococcus aureus Infections in Adults and Children. Clinical Infectious Diseases. 2011;52:e18-e55.

[11] Nguyen HM, Graber CJ. Limitations of antibiotic options for invasive infections caused by methicillin-resistant Staphylococcus aureus: is combination therapy the answer? Journal of Antimicrobial Chemotherapy. 2009;65:24-36.

[12] Stein GE, Wells EM. The importance of tissue penetration in achieving successful antimicrobial treatment of nosocomial pneumonia and complicated skin and soft-tissue infections caused by methicillin-resistant Staphylococcus aureus: vancomycin and linezolid. Curr Med Res Opin. 2010;26:571-88.

[13] Kocher S, Müller W, Resch B. Linezolid treatment of nosocomial bacterial infection with multiresistant Gram-positive pathogens in preterm infants: a systematic review. International journal of antimicrobial agents. 2010;36:106-10. 
[14] Chen H, Du Y, Xia Q, Li Y, Song S, Huang X. Role of linezolid combination therapy for serious infections: review of the current evidence. European Journal of Clinical Microbiology \& Infectious Diseases. 2020;39:1043-52.

[15] Jang HC, Kim SH, Kim KH, Kim CJ, Lee S, Song KH, et al. Salvage treatment for persistent methicillin-resistant Staphylococcus aureus bacteremia: efficacy of linezolid with or without carbapenem. Clin Infect Dis. 2009;49:395-401.

[16] Garazzino S, Tovo P-A. Clinical experience with linezolid in infants and children. Journal of Antimicrobial Chemotherapy. 2011;66:iv23-iv41.

[17] Porta A, Esposito S, Menson E, Spyridis N, Tsolia M, Sharland M, et al. Off-label antibiotic use in children in three European countries. Eur J Clin Pharmacol. 2010;66:919-27.

[18] Deville JG, Adler S, Azimi PH, Jantausch BA, Morfin MR, Beltran S, et al. Linezolid versus vancomycin in the treatment of known or suspected resistant gram-positive infections in neonates. The Pediatric infectious disease journal. 2003;22.

[19] Thibault C, Kassir N, Goyer I, Théorêt Y, Litalien C, Moussa A, et al. Population Pharmacokinetics of Intravenous Linezolid in Premature Infants. The Pediatric infectious disease journal. 2019;38:82-8.

[20] Shibata Y, Yamagishi Y, Mikamo H, Kato H, Nishiyama N, Asai N, et al. Comparative study on safety of linezolid and vancomycin in the treatment of infants and neonates for Gram-positive bacterial infections. Journal of Infection and Chemotherapy. 2018;24:695-701.

[21] Bayram N, Düzgöl M, Kara A, Özdemir FM, Devrim i. Linezolid-related adverse effects in clinical practice in children. Arch Argent Pediatr. 2017;115:470-5.

[22] Simon A, Müllenborn E, Prelog M, Schenk W, Holzapfel J, Ebinger F, et al. Use of linezolid in neonatal and pediatric inpatient facilities - results of a retrospective multicenter survey. European Journal of Clinical Microbiology \& Infectious Diseases. 2012;31:1435-42.

[23] Garazzino S, Krzysztofiak A, Esposito S, Castagnola E, Plebani A, Galli L, et al. Use of linezolid in infants and children: a retrospective multicentre study of the Italian Society for Paediatric Infectious Diseases. Journal of Antimicrobial Chemotherapy. 2011;66:2393-7. [24] Singh SR, Bacon AE, Young DC, Couch KA. In Vitro 24-Hour Time-Kill Studies of Vancomycin and Linezolid in Combination versus Methicillin-Resistant Staphylococcus aureus. Antimicrob Agents Chemother. 2009;53:4495-7.

[25] Grohs P, Kitzis MD, Gutmann L. In vitro bactericidal activities of linezolid in combination with vancomycin, gentamicin, ciprofloxacin, fusidic acid, and rifampin against Staphylococcus aureus. Antimicrob Agents Chemother. 2003;47:418-20.

[26] Jacqueline C, Caillon J, Le Mabecque V, Miegeville AF, Donnio PY, Bugnon D, et al. In vitro activity of linezolid alone and in combination with gentamicin, vancomycin or rifampicin against methicillin-resistant Staphylococcus aureus by time-kill curve methods. J Antimicrob Chemother. 2003;51:857-64.

[27] Ribes S, Pachón-Ibáñez ME, Domínguez MA, Fernández R, Tubau F, Ariza J, et al. In vitro and in vivo activities of linezolid alone and combined with vancomycin and imipenem against Staphylococcus aureus with reduced susceptibility to glycopeptides. Eur J Clin Microbiol Infect Dis. 2010;29:1361-7.

[28] Ilarslan E, AydÊn B, Kabatas EU, Beken S, Dilli D, Zenciroglu A, et al. Cataract in a preterm newborn: a possible side effect of linezolid therapy. J Coll Physicians Surg Pak. 2014;24:S281-3. 
[29] Narita M, Tsuji BT, Yu VL. Linezolid-associated peripheral and optic neuropathy, lactic acidosis, and serotonin syndrome. Pharmacotherapy. 2007;27:1189-97.

[30] Ozkaya-Parlakay A, Kara A, Celik M, Ozsurekci Y, Karadag Oncel E, Ceyhan M, et al. Early lactic acidosis associated with linezolid therapy in paediatric patients. International journal of antimicrobial agents. 2014;44:334-6.

[31] Zou D, Xu P, Zhang Y, Lu C, Wang J, Leng B, et al. The first case of teeth discoloration induced by linezolid in children in China Mainland. Journal of Infection and Chemotherapy. 2020.

[32] Ocampo PS, Lázár V, Papp B, Arnoldini M, Abel zur Wiesch P, Busa-Fekete R, et al. Antagonism between Bacteriostatic and Bactericidal Antibiotics Is Prevalent. Antimicrob Agents Chemother. 2014;58:4573-82.

[33] Baddour MM, Abuelkheir MM, Fatani AJ. Trends in antibiotic susceptibility patterns and epidemiology of MRSA isolates from several hospitals in Riyadh, Saudi Arabia. Ann Clin Microbiol Antimicrob. 2006;5:30-. 